\title{
Mentalisation and metaphor in poetry and psychotherapy ${ }^{\dagger}$
}

\author{
Jeremy Holmes
}

\begin{abstract}
People turn to poetry and to psychotherapy when in states of heightened emotion - love, elation, despair, death and loss. Through the analysis of a particular poem this article suggests that there are formal similarities between poetry and psychotherapy that can illuminate the workings of the latter. Perhaps the most overarching of these is mentalisation: the capacity to 'think about feelings' or to be 'mind-minded'. Finding the 'right words in the right order' is a task for therapists and their patients as well as for poets, since the appropriate image or metaphor can mirror or evoke feelings in the listener in a way that facilitates empathic attunement. If feelings can be objectified, their power to distress or overwhelm is mitigated. Thus, poetry and psychotherapy are similarly concerned with processes of repair of the human experiential and communicative fabric.
\end{abstract}

In an attempt to establish strengths as well as pathology, part of my routine history-taking involves asking patients what they are interested in and what they enjoy doing. Rarely, if ever, does reading or writing poetry come as the answer. Poetry is definitely a minority interest. Nevertheless, at times of emotional intensity, whether painful or joyful, people often turn to poetry, trite or great, as a means of containing and expressing their feelings. Since those moments are central to what we do as psychiatrists and psychotherapists, if we wish to enhance the depth and quality of our work it is perhaps worth putting indifference or antipathy to one side, and listening to what poets have to tell us. There is evidence there, albeit of the experiential, qualitative variety.

We can never have direct access to another's feelings. We use metaphors to help us reach into the inner world of another person. We ask, 'What did it feel like when your mother died, your partner abandoned you, you felt people could read your feelings...?' As E. M. Forster said - everything is like something else. When a patient tells us what his depression is like we begin to put ourselves into his place - 'It's like being in a dark room and not being able to find the way out'; now we can identify with an aspect of his experience.

Prescribing an antidepressant may require little explication beyond working out indications and

See pp. 163-166 and 182, this issue. dosage. An SSRI is an SSRI is an SSRI. The same might even be true for brief manualised therapies. By contrast, knowing how to respond - what, if anything, to say and how - when a patient unexpectedly bursts into tears, or arouses strong feelings of irritation, attraction or sympathy in us, cannot easily be encompassed within guidelines, protocols or manuals. This is where we need metaphors, although in one sense poetry is just one metaphor among many. There may be as many psychotherapeutic lessons to be learned from a life drawing class, in which a combination of empathic identification with the body to be depicted and objective appraisal of its lineaments is required, as will be gained from poetry. If your passion is golf - or even if it isn't - then teeing up, getting lost in the rough, holing in one and so on will serve for describing some of the ups and downs of a typical psychiatric day. Since, however, the core business (oh dear, managerial metaphors have crept in) of poetry is metaphor - finding the right words in the right order to communicate about our affective life - I suggest that it has a special contribution to make to psychotherapeutic work.

\section{Poetic and psychotherapeutic parallels}

Let us go straight to a specific poem and see how unravelling its mechanics might illuminate what psychotherapists get up to. Here is Dinner with My Mother by the contemporary British writer Hugo

Jeremy Holmes is a retired consultant psychiatrist in North Devon and Visiting Professor of Psychotherapy at the University of Exeter (Department of Clinical Psychology, University of Exeter, Exeter EX4 4QG, UK. Email: j.a.holmes@btinternet.com). He works part-time as a psychoanalytic psychotherapist. His current professional interests include the psychotherapeutic implication of attachment theory, and common factors in psychotherapy. He occasionally writes a poem, never for publication. 
Williams (1994). Biographical information on the author would no doubt help illuminate aspects of the poem, but the reader is invited to consider the poem as a self-sufficient 'subjective-object', just as it is sometimes desirable to respond to an account of a psychotherapy session as an event in its own right, without the possibly obscuring impact of excessive life-history data.

Like a case history, my hope is that it provides qualitative evidence of the power and relevance of poetry. I have chosen it, from myriad possible examples, because it is accessible, short, 'good' (i.e. in my judgement, emotionally authentic and beautifully crafted) and describes a seemingly everyday event but with strong emotional overtones which might crop up in a routine psychotherapy session. The title and content are self-explanatory.

\section{Dinner with my Mother}

My mother is saying 'Now'.

'Now', she says, taking down a saucepan, putting it on the stove.

She doesn't say anything else for a while,

so that time passes slowly, on the simmer, until it is 'Now' again

as she hammers out the steaks

For Steak Diane.

I have to be at hand at times like this for table-laying, drink replenishment and general conversational encouragement,

but I am getting hungry

and there is nowhere to sit down.

'Now,' I say, making a point

of opening a bottle of wine.

My mother isn't listening.

She's miles away,

testing the sauce with a spoon,

narrowing her eyes through the steam.

'Now,' she ways very slowly, meaning

which is it to be,

the rosemary or the tarragon vinegar

for the salad dressing?

I hold my breath, lest anything

should go wrong at the last minute.

But now it is really 'Now',

our time to sit and eat.

From Dock Leaves (1994), (C Hugo Williams, used by permission of the author and the publisher.

Let us suppose that part of the impulse to write a poem, or to consult a psychiatrist or psychotherapist, comes from the need to make sense of, or do psychic work on, something that seems painful, confusing or troubling in the subject's mind. Let us assume too, or even hope, that both psychotherapy and poetics have a reparative function - a patient of mine, with a long career of self-harm, managed to keep away from cutting herself for 6 months while writing a daily poetic account of the miseries of her life. Can we learn something about the minutiae of the reparative process by comparing the poetic and psychotherapeutic processes? I select seven aspects where parallels are to be drawn between poetising and psychotherapising.

\section{Mentalisation}

'Mentalisation' is a recently emerged overarching concept in the field of attachment research and the treatment of disorganised attachment in children and borderline personality disorder in adults (Allen \& Fonagy, 2006). To mentalise is to be 'mind-minded'; to see ourselves from the outside ('as others see us') and others from the inside. Mothers who can mentalise are more likely to have securely attached children (Slade, 2005), and adults who fail to mentalise are at risk of being overwhelmed by their feelings and by problematic relationships with others (Fonagy et al, 2002; Bateman \& Fonagy, 2004). Mentalisation is fostered by, and fosters, secure attachment. Both poetry and psychotherapy can be seen as attempts to think about feelings and to 'feel about thinkings': that is the essence of mentalisation. We sense here Williams using the space provided by his poetic form to explore the difficult emotions aroused in him by both wanting to please and get close to, but also being irritated by, his mother. For mentalisation to operate there has to be a safe space, both literally in the therapist's room and figuratively in his or her mind. The therapist's 'frame' (consistency of space, place, time, structure) and the poetic form (the bounded 'empty space' of the blank page, structures of stanza, rhyme and rhythm) provide this.

\section{The search for emergent meaning}

In both a psychotherapeutic session and a poem there is a dialectic between known form and unstructured space that facilitates new or 'emergent' meanings (Margison, 2002). The structure of the session is formalised and familiar, yet neither patient nor therapist knows in advance what is going to 'happen' during the 50 minutes of their session/sitting - other, perhaps, than that there will be moments of both meeting and missing. Similarly Williams's poem, with its careful arrangements of groups of four lines and steady metrical beat, has a formal structure which allows for the containment of uncertainty and tension - we don't know at the start if that meal is ever going to get onto the table. Attachment theory posits a dialectic between security and exploration. The 'subject' of both poetry and psychotherapy is the processing of difficult feelings. Such feelings are liable to trigger attachment behaviour - seeking a 
secure base - which is inimical to exploration and mentalisation. The security provided by the therapeutic situation, and by poetic form, assuages attachment behaviours and allows for the emergence of playfulness and exploration.

\section{Recursiveness}

A therapy session, like a poem, being bounded, has a beginning, a middle and an end - and often in its end is its beginning. There is thus a recursive aspect to a poem and a psychotherapy session. Williams's deceptively simple poem loops back on itself, while its sense emerges slowly only on careful second and third readings. The oft-repeated 'Now' turns from an initial verbal mannerism into a philosophical statement of the value of two people being present to one another and, finally, in the same place at the same time. Similarly, unravelling the meaning of a psychotherapy session in supervision is often helped by looking back at the opening moments in the light of subsequent developments. A casual remark about the weather as the patient enters the therapy room may, as it turns out, reflect her underlying emotional tone. A patient who comments that he is late because he has 'had difficulty in parking' may be wondering whether the therapist really has sufficient space to accommodate his neediness.

\section{'Action replay'}

Wordsworth famously defined poetry as 'emotion recollected in tranquillity' (1802). Both lyric poetry and psychoanalytic work have the capacity to focus on tiny fragments of experience, to slow them down, replay them, tracing their emotional links backwards in time and sideways with other sets of experiences and emotions. Subjecting one's experience to this type of slowed-down close reading is synonymous with mentalisation. The whole poem can be seen as Williams's attempt to take his mother's 'Now' and, frame by frame, to put it under the poetic microscope.

\section{Somatosensory experience}

Both poem and session are somatosensory experiences reaching consciousness through what Ogden (1989: p. 76), following Bion, calls 'reverie', i.e. the therapist's 'day-dreams, fantasies, ruminations, bodily sensations, derivatives of unconscious intersubjective constructions'. The capacity to weave conscious and useful thoughts out of these dreamlike elements is for Ogden the crucial contribution of psychoanalysis to the achievement of psychic health.
Although the medium of communication is primarily verbal, as therapists or psychiatrists our initial response to patients is often physical. A supervisor reported that in the course of a session her patient had described a friend as having 'passed away'. The use of this conventional term jarred (note the physicality of the metaphor, albeit one that is near-dead) on her consciousness, although she could not initially say why this was. Further exploration revealed that in fact the death had been suicide and thinking about that had been unbearably painful for this patient, whose mother had similarly killed herself when the patient was a child, so much so that she had to wrap the event up in a euphemism.

Comparably, the music of Williams's poem - its steady, almost stately, metre, the repetitions and dreamy rhythms interrupted by the abruptness of phrases and words like 'hammer out' and staccato 'steak'- enables it to penetrate, to be physically absorbed into our body / mind, and, once inside, for us to be able to think (or in Ogden's sense, dream) about it and its multiple meanings. In both poetry and psychotherapy there is a dialectic between feelings and language. Identifying and then finding what initially may be no more than a vague shape for these feelings leads on to the attempt to find words to describe them, and via the process of mentalisation, to begin to arrive at meaning. The therapist's task is to 'read' the 'text' which the patient brings, 'backtranslating' words into affective/bodily experience. She does this by the reverse process within herself, 'reading' her own physical and emotional responses (countertransferences), and then finding words to capture these.

These interpersonal physiological sensations invariably have a temporal aspect - they are 'feelings in time', and this is often a pointer to their meaning. This is manifest in both poem and session by the balance between tension and its resolution. Psychoanalytically (using the word to encapsulate a group of metaphors deriving from early childhood and infancy), the poem could be compared to the struggle of an infant at the breast, gripped by hunger, longing to 'latch on' to a slightly distracted and selfpreoccupied mother. One reading of 'Dinner with My Mother' might imagine a final moment of bliss when breast and nipple come together via the let-down reflex and the milk begins to flow: 'our time to sit and eat'. An alternative take on the poem might view the bleakness of the non-meeting of preoccupied mother and son continuing right through to a miserable end: the protagonist in the poem needs to open a bottle of wine in order to tolerate his mother's mild narcissism and self-preoccupation. In both versions there is a rupture and attempt at repair, successful or unsuccessful. 


\section{Self-referentiality}

The emphasis on the transference and countertransference matrix as the core theme of contemporary psychoanalytic psychotherapy means that every story, reaction, feeling and experience brought to the session has to be examined in the light of the relationship between therapist and patient. A psychotherapy session has an intrinsically selfreferential quality that sets it apart from 'ordinary' discursive discourse - the therapist has always to be asking himself, 'What has all this got to say about "us"?' Thus, when a patient starts talking in therapy about needing to find a driving instructor the therapist must wonder whether she is looking for more guidance than she feels she is getting in the therapy, and how this links to her absent father in childhood.

Similarly, there is a case to be made that most poems contain explicit or covert reference to the act of poetry-making itself. Williams, like his mother, is 'hammering out' something in his poem - using words and the patterns they create to make sense of an experience. The poet has to choose his words as carefully as finding the right dressing for a salad. The poem, like the meal, is 'simmering' in his mind, nothing is said, until the 'Now' moment, when it can be written down, arises. The capacity to 'think about thinking' implicit in this self-referentiality is a key feature of mentalisation. The mentalising mother is able to feel her feelings towards her infant-overwhelming love, protectiveness, anxiety, frustration, fury, etc., and at the same time to be able to be aware that she is feeling these things, and to use them to repair interruptions in the continuity of their relationship.

\section{Objectification}

As an artefact, the poem itself is present to the reader over and above the events and objects to which it refers. That is what gives it its objectivity and general relevance. Williams's poem is not just an account of a mother and son preparing supper - it is about mother-love, filial love, unmediated Oedipal love, the gulf between the generations and much else. The poem reads us - in that it evokes particular feelings and memories in its readers - just as much as we read it. Poetry presents our feelings to us in an objectified way - it mentalises them for us. The poet is always in a dyadic relationship to his material. Out of the nothing of the blank piece of paper she creates an other, with whom she begins to have a conversation - the nothingness of which could be construed as an ultimate rent in the continuity of existence. What finally emerges as the poem is her attempt to make sense of that conversation. This can be compared to Ogden's (1989) notion of the 'analytic third' - the therapeutic relationship itself, a joint creation, that cannot be predicted or reductionistically derived from the patient's pathology alone.

In Williams's poem the protagonist oscillates between intimacy and disconnection with his mother, as depicted. As a session ends and the next is anticipated, the never-ending movement between absence and presence, loss and recovery, is the grist of psychotherapy. A poem is a device for turning subjectivity of feelings into sharable objectivity. A psychoanalytic session, via its focus on the relationship between therapist and patient, is a device for exploring and containing the 'fort and $d a^{\prime}$ ('gone' and 'there': Freud, 1920) of relationships. The objectification of the inevitable misunderstandings, exploitations, absences and failures of communication is an essential step in the process of repair, of returning the fort back to $d a$. Both poetry and psychotherapy can be seen as reparative in this sense.

\section{Discussion}

Bion (1978) saw thinking as arising directly out of absence - 'no breast, imagine a breast'. In a more restricted sense mentalisation can be viewed as enabling us to cope with the inevitable breaches, lapses, lacunae, failures, narcissistic self-preoccupations, disruptions and potential traumata of everyday life. Mentalisation provides a reparative bridge over the chasm of loss.

The Kleinian view of creativity is that it is reparative - a way of making good the psychic devastation wrought by aggression unleashed in the face of deprivation and absence - the murderous and murdered 'bad breast', full of projected hatred, is brought back to life through reparative activity (Segal, 1990). By contrast, my argument here is that mentalisation is one of the ways in which we survive the losses and breaks in the network of support, whether these are minor or major. Children who can articulate their perception of their caregivers as stressed, intoxicated, depressed and so on are better protected against disorganisation of their attachment representation than are those who cannot make that judgement (Fonagy et al, 2002; Slade, 2005). Similarly the ability to recognise one's own feelings of rage or aggression or despair for what they are - ultimately 'just thoughts' - is a bulwark against self-destructive acting out. Most therapies for borderline personality disorder, whether they be behavioural, dialectically Buddhist, transference-focused or Kleinian, make the fostering of this capacity, or skill, their aim.

Where does poetry fit in with this viewpoint? First, there is a powerful link between poetry and loss - people turn to poetry at moments of great joy or great sadness, either because there is an intrinsic awareness that happiness cannot last for ever, or 
in an attempt to re-establish the fabric of existence ruptured through death or separation.

Second, the business of poetry is to generate truthful and beautiful images, i.e. feeling-toned mental representations of experience, through which the 'lost object' can be 'reinstated' (Segal, 1990) in the mind. The external object is lost, but mental continuity still maintained. Poetry has the power to conjure up images in the internal world in a way that keeps the ongoingness of reality intact in the face of loss.

Third, Lacan (1977) has argued that as a child acquires language and enters the 'symbolic order', this disrupts the primordial unity and seamless flux of existence. Poetry, through rhyme, rhythm, metre, tempo, tone and assonance, helps to reestablish connection and continuity between words and the objects they represent (the signifiers they signify), and thus, at least partially, to reverse this inescapable alienating trend. This connectivity of poetry - the way that rhymes, beat, images get 'into' us - is comparable to the 'scaffold' of the psychotherapeutic session. The poem becomes a living thing that 'holds' us for the duration of our attention to it. Similarly, a held child/patient can use mentalisation to overcome despair, and thus hold hope in mind. We habitually try to avoid, blot out or kill the pain which life, especially when traumatic, inflicts on us, but as Ogden (1999: p. 992) puts it, 'we turn to poetry and to psychoanalysis ... with the hope that we might reclaim (or perhaps experience for the first time) forms of human aliveness that we have foreclosed to ourselves'. Minority interests both may be, but society needs poetry, and psychiatry psychoanalytic psychotherapy, as part of that vital process of staying alive.

\section{Declaration of interest}

None.

\section{References}

Allen, J. \& Fonagy, P. (2006) (eds) Handbook of Mentalization-Based Treatment. John Wiley \& Sons.

Bateman, A. \& Fonagy, P. (2004) Psychotherapy for Borderline Personality Disorder. Oxford University Press.

Bion, W. (1978) Sao Paulo clinical seminars. Reprinted (1987) in Clinical Seminars and Four Papers (ed. F. Bion), pp. 131-222. Fleetwood Press.

Fonagy, P., Gergeley, G., Jurist, E., et al (2002) Affect Regulation, Mentalisation, and the Development of the Self. Other Press.

Freud, S. (1920) Beyond the pleasure principle. Reprinted (1953-1974) in the Standard Edition of the Complete Psychological Works of Sigmund Freud (trans. and ed. J. Strachey), vol. 148, pp. 14-15. Hogarth Press.

Lacan, J. (1977) Ecrits: A Selection (trans. A. Sheridan). Norton.

Margison, F. (2002) Psychodynamic interpersonal therapy. In Integration in Psychotherapy: Models and Methods (eds J. Holmes \& A. Bateman), pp. 107-124. Oxford University Press.

Ogden, T. (1989) The Primitive Edge of Experience. Karnac.

Ogden, T. (1999) 'The music of what happens' in poetry and psychoanalysis. International Journal of Psychoanalysis, $\mathbf{8 0}$ 979-994.
Segal, H. (1990) Dream, Phantasy, Art. Routledge.

Slade, A. (2005) Parental reflective functioning: an introduction. Attachment and Human Development, 7, 269-282.

Williams, H. (1994) Dock Leaves. Faber \& Faber.

Wordsworth, W. (1802) Lyrical ballads, Preface to 2nd edn. Reprinted (1990) in Oxford Dictionary of Quotations (3rd edn with corrections), p. 583. Oxford University Press.

\section{MCQs}

1 Poetry:

a is enjoyed by most people

$\mathrm{b}$ is often turned to at times of heightened emotion

c is always obscure

d must rhyme and scan to be worth the name

e was never quoted by Freud to support his arguments.

\section{Psychotherapy:}

a is concerned more with behaviours than with words

b pays attention, like poetry, to the precision of words

c like poetry, has no relevance to everyday life

d works when the patient agrees with the therapist's interpretations

e should, like poetry, be funded by the Arts Council rather than the Medical Research Council.

\section{Mentalisation:}

a means being 'mind-minded'

b refers to the capacity to get in touch with one's masculinity

c was first described by William Wordsworth

$\mathrm{d}$ is synonymous with the defence of intellectualisation

e is overactive in people with borderline personality disorder.

\section{Reparation:}

a in psychotherapy refers exclusively to the repair of communication lapses

b is a term used only in Kleinian psychoanalysis

c is a useful metaphor for psychic change

$\mathrm{d}$ is almost never needed in everyday life

e only occurs in fee-paying therapies.

\section{Bion:}

a was a well-known First World War poet

b analysed the writer W. H. Auden in the 1930s

c developed a mathematical grid that the patient helped to fill in

d said that analysts should be supportive and friendly

e theorised the process of thinking.

\begin{tabular}{|lllllll|}
\hline \multicolumn{2}{|l}{ MCQ answers } & & & & & \\
1 & & 2 & 3 & 4 & 5 & \\
a F & a F & a T & a F & a F \\
b T & b T & b F & b F & b F \\
c F & c F & c F & c T & c F \\
d F & d F & d F & d F & d F \\
e F & e F & e F & e F & e T \\
\hline
\end{tabular}

